\title{
Finns det antisionism i den marxistiska kritiken av Moses Hess?*
}

\author{
Svante Lundgren
}

Åbo

\section{Inledning}

En av de mest betydande protosionisterna, författaren till den sionistiska klassikern Rom und Jerusalem, Moses Hess (1812-75), var samtidigt en av sin tids ledande socialister. Eftersom han var den första i Tyskland som både skrev socialistiska skrifter och deltog i politisk verksamhet brukar han ibland betraktas som den första tyska kommunisten. År 1903 lät socialdemokraterna i Köln inrista orden "Vater der deutschen Sozialdemokratie" på hans gravsten. Hess' inflytande på Karl Marx var också större än vad man ofta ansett, inte minst bland marxistiska forskare. ${ }^{1}$ Som socialistisk pionjär i Tyskland skrev han, 35 år före den sionistiska rörelsen, en kraftfull bok om ett nationellt uppvaknande bland judarna och om en judisk stat i Palestina. ${ }^{2}$

I Kommunistiska manifestet angreps Hess hårt av sina tidigare vänner och medkämpar Marx och Engels. På grund av detta anatema över Hess har han blivit minst sagt styvmoderligt behandlad i officiell socialistisk historieskrivning och av marxistiska forskare. Ett exempel på detta är att Hess i det östtyska storverket om den tyska arbetarrörelsens historia, utgivet av Institut für Marxismus-Leninismus beim Zentralkomitee der SED, omnämns en enda gång. 3

Det har naturligtvis också funnits undantag från denna regel. Ett av dessa utgör Franz
Mehring, som har skrivit en av de mest kända biografierna over Marx. Trots att en senare marxolog kallat Mehrings biografi "slightly hagiographical" 4 behandlar den Hess förvånansvärt fördomsfritt. Mehring berömmer Hess för hans insats inom tysk socialdemokrati och om Kommunistiska manifestets hårda ord om Hess säger Mehring: "Das war arg übertrieben, soweit es auf die Sache, und ganz ungerecht, soweit es auf die Personen ankam." ${ }^{5}$ Hess' senare sionistiska aktivitet omnämner Mehring överhuvudtaget inte.

Syftet med denna artikel är att utröna om det finns antisionistiska drag i de bedömningar av Hess som olika marxister under vårt århundrade har gjort. Utan att gå in på definitionsfràgor talar jag om antisionism och inte om antisemitism. Ingen marxist skulle säga att Hess var en så misslyckad socialist för att han var jude. Däremot är det fullt troligt att man har hāvdat att Hess' sionistiska engagemang ār ett bevis för att han aldrig förstod den "vetenskapliga socialismen". 6

Många marxistiska historiker och teoretiker har inte skrivit en enda rad om Hess, och en del av dem som har gjort det har inte överhuvudtaget behandlat hans sionistiska engagemang. De som tas upp i denna artikel är de som har behandlat Hess i skrift och som då också uppmärksammat att han var sionist. 
Eftersom den vetenskapliga produktionen om Marx och marxismen omfattar flera miljoner titlar är det omöjligt att göra en fullständig oversikt. Månget verk om Marx eller marxismen, vilket jag inte känner till, kan innehålla någonting om Hess. Den litteratur som primärt handlar om Hess har jag i varje fall beaktat.

\section{Eduard Bernstein och Julius Motteler}

Under en lång tid fördes den s.k. revisionismstriden inom den tyska socialdemokratin. I den stod en ortodox marxistisk fraktion, ledd av Karl Kautsky, emot en revisionistisk grupp, ledd av Eduard Bernstein. Denna splittring skulle på 1910-talet leda till att den socialistiska arbetarrörelsen slutligen uppdelades i en kommunistisk och en socialdemokratisk gren.

Moses Hess var vid denna tid död sedan lānge, men kom ändå att spela en viss roll i striden mellan Kautsky och Bernstein. Bernstein hade nämligen upptäckt den $\mathrm{i}$ övrigt nästan helt bortglömde Hess och blivit så begeistrad att han översatte och publicerade Hess' artikel Jugement dernier du vieux monde social. ${ }^{7}$ I en inledning hävdade Bernstein att artikeln teoretiskt stod "auf der Höche des socialistischen Wissens ihrer Zeit". ${ }^{8}$ Bernstein försvarar också Hess mot Marx och Engels och hävdar att deras dom i Kommunistiska manifestet var orättvis. ${ }^{9}$

Att Bernstein hade en positiv inställning till Hess, som så bespottats i Kommunistiska manifestet, var for Kautsky \& consortes ytterligare ett bevis för revisionismens fördärvlighet. Detta framgår mer än tydligt av fem brev, som föreståndaren för det socialdemokratiska partiarkivet, Julius Motteler i januari 1903 skrev till Kautsky. ${ }^{10}$

Situationen var följande: Två sionister, Arthur Meyerowitz och Theodor Zlocisti (han som senare skrev den första biografin över Hess 1905), hade vänt sig till Paul Trapp, det tyska socialdemokratiska partiets representant i $\mathrm{Pa}$ ris, med en begäran om att få tillgång till det Hess-material som uppbevarades i partiarki- vet. I två brev till Motteler, den 5.12. 1902 och 8.1. 1903, ${ }^{11}$ framställer Trapp de båda sionisternas önskan och omtalar också att dessa stått i kontakt med Bernstein, som intresserat stödde Meyerowitz' och Zlocistis planer på en biografi över Hess.

I sina brev till Kautsky uppvisar Motteler enorma fördomar mot Hess, Bernstein och allt vad sionism heter. Brevväxlingen ägde rum kort efter att Bernstein hade publicerat Hess' artikel i Documente des Socialismus. Motteler skriver att denna artikel innehåller antimarxistisk revisionism och fortsätter: " ...daraus folgerte ich, dass Meyerowitz Ausschicksmann und Mitarbeiter Edes [Bernsteins] sein könnte als zionistischer Mitarbeiter an den Documenten $d: S . " 12$ I ett senare brev ${ }^{13}$ skriver Motteler att publiceringen av Hess' artikel "scheint erwünscht", eftersom sionismen och revisionismen sitter "gemeinsam in der Tinte".

Också Hess' änka, Sibylle Hess, drogs in i detta spel. Enligt Motteler ${ }^{14}$ ville hon att hennes man skulle bli ihågkommen som socialist, inte som sionist. Hon ville inte alls ha att göra med "die Zionisterei". ${ }^{15}$ I ett tidigare brev ${ }^{16}$ talar Motteler både om "Zionisterei" och "Meyer-Bernsteinowitzerei".

I ett brev av den 10.1. $1903^{17}$ ironiserar Motteler över sionisternas "Prophetensuche" (Meyerowitz hade i ett brev till fru Hess ${ }^{18}$ skrivit att många unga judar ser upp till Hess som en profet). I ett brev till Trapp hade Meyerowitz meddelat att Bernstein var mycket angelägen om att publicera Hess' skrifter. Motteler ironiserar över Bernstein med en allegori om Mose och vattnet i klippan och skriver att partistyrelsen borde få se Meyerowitz' alla brev, "... damit dieselbe sieht, wie die Herren M:wizt $\&$ Freunde Hess für die Zionistensache benutzen wollen und sicher nicht zum Nutze des Socialismus." 19

Mottelers brev ger uttryck inte bara for stark antipati mot Bernstein, utan också mot sionismen. Motteler var nära förbunden med Kautsky och delade dennes negativa syn på sionismen. Det är också intressant att Bernstein vid den här tiden var motståndare till sionismen, som han först senare blev välvilligt inställd till. ${ }^{20}$ Trots det ställde han sig helt positiv till Hess och till sionisternas planer på 
att publicera Hess' skrifter och en biografi över denne.

Hur gick det till sist med Hess-materialet i partiarkivet? Partistyrelsen beslöt att materialet skulle vara tillgängligt för alla intresserade, ${ }^{21}$ så Zlocistis och Meyerowitz' planer kunde förverkligas (Zlocisti utgav sedan en biografi över Hess och två samlingar med artiklar av denne). Redan av rent historiografiska skäl är Mottelers och Kautskys agerande emellertid märkligt. ${ }^{22}$

\section{György Lukács}

En av 1900-talets stora marxistiska teoretiker, ungraren György (Georg) Lukács, skrev en artikel om Hess år 1926. ${ }^{23}$ Lukács är kritisk mot Hess, vilket inte är särdeles överraskande. Han förnekar att Hess i någon högre grad skulle ha påverkat Marx. Lukács bedömer Hess' idéer utifrån den s.k. vetenskapliga socialismens fasta norm, och då de skiljer sig från denna kan Lukács slå fast att Hess som teoretiker är "zugrunde gegangen". ${ }^{24}$ Fastän Hess hyllade Marx som teoretiker kunde han, enligt Lukács, aldrig riktigt förstå denne. Därför kännetecknas Hess' skrifter-också efter hans s.k. omvändelse till Marx-av "ein hilfloses Hinundhertaumeln zwischen ganz leeren und abstrakten Gedankenkonstruktionen, phantastischen Konzeptionen einer Naturphilosophie, rassentheoretisch-geschichtsphilosophischer Begründung des Zionismus etc. 25

För Lukács ār Hess' sionism alltså dels ett uttryck för tomma tankekonstruktioner och dels ett bevis för att han, trots att han lovordade Marx' idéer, aldrig förstod dennes lära. Då Lukács ändå berömmer Hess for att ha varit en ärlig revolutionär och för att till sin död ha stått på det kämpande proletariatets sida, kunde Lukács' omdōme om Hess kanske enklast beskrivas med Runebergs ord om Sven Dufva: "Ett enkelt huvud hade han, men hjärtat det var gott."

\section{Irma Goitein}

År 1931 publicerade Irma Goitein ett arbete om Hess' utveckling åren 1837-51 som ett "Beiheft" till den ansedda tidskriften Archiv für die Geschichte des Sozialismus und der Arbeiterbewegung. ${ }^{26}$ Som bilagor publicerades 14 artiklar eller brev av Hess; en del av dem hade aldrig tidigare publicerats, andra var mycket svårtillgängliga.

Goitein analyserar Hess' socialism lika som Lukács, vilket hon också deklarerar redan $\mathrm{i}$ inledningen. ${ }^{27}$ Hon kallar genomgående Hess' socialism "idealistisk-utopisk", vilket närmast är ett skällsord för en renlärig marxist. Det att Hess från år 1846 skulle ha anammat Marx' idéer betecknar hon som skenbart.

För vårt ämne är bokens två sista stycken särskilt intressanta. Här hävdar Goitein igen att Hess aldrig riktigt förstod Marx' lära, att den bara var en "Verkleidung" för honom. Hess ska visserligen själv ha trott på denna forklädnad så länge den sammanföll med hans filosofiska övertygelse, men i krisens stund föll den: vid revolutionen år 1848 kom Marx' teorier i konflikt med Hess' aktivistiska natur. Därefter ska Hess ha återvänt till sina tidigare uppfattningar, inte på grund av att de bättre forklarade tidshändelserna, utan för att de rättfärdigade och bekräftade hans viljemässiga aktivitet. Goitein fortsātter: "Hier erklärt sich auch die Entwicklung, die Hess seitdem genommen hat: seine agitation für die Sache Lassalles und seine Antizipation des Zionismus." 28

Det är inte alldeles lätt att förstå vad Goitein menar med detta. Av allt att döma vill hon säga att Hess' sionism inte bottnade $i$ att han förnuftigt och teoretiskt ska ha övervägt frågorna, utan att han ville legitimera sina egna onskningar. Redan tidigare ${ }^{29}$ har Goitein talat om Hess' immanenta judendom, som då och då slår igenom $\mathrm{i}$ hans tänkande. Trots de knappa och tvetydiga formuleringarna får jag ett intryck av att Goitein ser det att Hess var sionist som någonting som bör läggas honom till last. 


\section{Ernst Bloch}

Vid sidan av Gyōrgy Lukács och några till ār Ernst Bloch en av 1900-talets stora marxistiska teoretiker. Han var själv jude och har visat stort intresse för religiösa frågeställningar.

I sin monumentala Das Prinzip Hoffnung har Bloch också ett avsnitt om sionismen..$^{30}$ I det behandlar han också Hess, som făr mycket beröm trots att Bloch också framhåller skillnaderna mellan Hess och Marx. Theodor Herzl kritiserar Bloch dāremot skarpt. Bloch beskriver genomgående judarna och judendomen vălvilligt och varmt.

Bloch har den traditionella marxistiska synen på sionism: alla nationalitetsproblem ska bli lösta i och med att det grundläggande samhällsproblemet löses, dvs. när produktionsmedlen kommer i samhällets ägo. Det bästa sättet att verka för att lösa ett nationalitetsproblem som t.ex. judefrågan är därför, enligt Bloch att kämpa för världsrevolution och socialism. "... es gibt keine isolierte Lösung irgendeines Minoritäten- oder Nationalitätenproblems an sich. Das bedeutet: es gibt keine Lösung der sogenannten Judenfrage, soweit sie besteht, ohne Gesamtlösung der ökonomisch-sozialen." 31

Bloch riktar i alla fall inte sin avvisande inställning till sionismen mot Hess, utan mot Herzl. Som socialist och "aufrechter Revolutionär bis zuletzt" ${ }^{32}$ ska Hess ha tagit sin utgångspunkt i judendomens profetiska tradition och velat se ett judiskt aktionscentrum i Palestina, genom vilket judarna kunde verka för socialismens seger $\mathrm{i}$ hela världen. I dagens situation (Bloch skrev Das Prinzip Hoffnung åren 193847) ska någon geografisk sionism inte längre behövas, utan judarna kan delta i frihetskampen tillsammans med alla andra. Detta skulle, menar Bloch, också Hess ha insett om han hade levat och placerat sitt Jerusalem, inte i Palestina, utan i Moskva. "...ubi Lenin, ibi Jerusalem" ${ }^{33}$ Om judendomen sedan är en nation eller inte, det ska inte spela någon roll. Det viktiga är att judarna är trogna det etiska imperativ som deras religion innehåller, dundrar Bloch och citerar bibeln (Jes. 42:1, 7, 11:9). Den messianska visionen vet, enligt Bloch, inga gränser, den lever där kampen för rättvisa förs, Sion finns ovverallt. Blochs slutsats blir: "In
Summa, diese partiale Bewegung könnte aufhören, ohne dass eine jüdische Komponente selber aufhörte, sei es als Volk, sei es-in bedeutend wahrerer Weise-als Zeuge und Zeugnis messianischer Gesinnung; Zionismus mündet im Sozialismus, oder er mündet überhaupt nicht." 34

Att sāga vad Hess skulle ha ansett om han hade levat i mitten av 1900-talet är naturligtvis ren och skär spekulation. På den punkten kan man varken verifiera eller falsifiera Blochs uppfattning. Med tanke på att Hess kraftigt betonat judendomens nationella karaktär, är det nog legitimt att formoda att Hess, som det heter, vānder sig i sin grav. Det är i alla fall intressant att Bloch enligt marxistisk tradition förkastar sionismen, men att han trots det strör beröm över Hess, vars syntes av judendomens profetiska karaktär och det revolutionära proletariatets historiska uppgift fascinerade Bloch. ${ }^{35}$

\section{Wolfgang Mönke}

Den marxistiske forskare som har skrivit mest om Hess är Wolfgang Mōnke. År 1961 utgav han Hess' filosofiska och socialistiska skrifter från åren $1837-50^{36}$ tillsammans med Auguste Cornu, och år 1964 publicerade han manuskript, brev och dagboksutdrag av Hess, ${ }^{37}$ som inte tidigare utgivits. Mönke har också skrivit artiklar om Hess samt en dissertation, vars senare del jag inte har fått låna från DDR. ${ }^{38}$

Mönke bedōmer Hess på ett traditionellt marxistiskt sätt. Hess ska ha stått för en filosofisk, utopisk, ovetenskaplig socialism, som ska ha besmittats av småborgerliga förestallningar. Att Marx och Engels fördömde den är, enligt Mönke, alldeles riktigt. I fråga om vilket inflytande Hess haft på Marx när det gäller alienationsbegreppet gör Mönke en intressant kovändning. I sin inledning till utgåvan av Hess' skrifter medger han att Hess har utōvat ett visst inflytande på Marx i den frågan. ${ }^{39}$ Några år senare hāvdar Mönke däremot att Hess' och Marx' åsikter åren 1843-44 
liknar varandra for att Marx ska ha påverkat Hess ! 40

I inledningen till Hess' filosofiska och socialistiska skrifter omnämner Cornu och Mönke ibland Hess' judiska och sionistiska intresse. Hess' andra bok anser de att var ett avsevärt framsteg $\mathrm{i}$ förhållande till debutboken, $\mathrm{i}$ vilken Hess knappt hade lösgjort sig från "den jüdischen Überlieferungen". 41 Rom und Jerusalem, som enligt Cornu/Mönke "die zionistische Bewegung einleitete", ska ha varit ett uttryck för att Hess inte kunde hålla fast vid politiska principer, att han var teoretiskt förvirrad och för en regression till barn- och ungdomsåren. Denna sionistiska skrift anser de teoretiskt stå långt under det som Hess skrev på 1840-talet. Cornu/Mönke bedömer Hess' sionistiska teorier kategoriskt: "Es bedarf keiner Erklärung, dass diese Theorie unverträglich ist mit der materialistischen Geschichtsauffassung von Marx." 42

År 1980 utkom den andra upplagan av Hess' filosofiska och socialistiska skrifter. Återgivningen av Hess' skrifter är identisk med den första upplagan, men inledningen-som Mönke denna gång skrivit ensam-är rätt kraftigt omarbetad. Han bedömer nu Hess betydligt positivare. Mönke kritiserar visserligen det idealistiskt-utopiska i Hess' tänkande och framhäver skillnaden mellan Hess' socialism och den "vetenskapliga socialismen", men Hess får också mycket beröm för sin insats inom tysk arbetarrörelse. Vi kan jämföra den första meningen i det avslutande, sammanfattande avsnittet i respektive upplaga.

1:a upplagan: Das Andenken, das die deutsche Arbeiterklasse Moses Hess bewahrt, ist nicht frei von Vorbehalten. ${ }^{43}$

2:a upplagan: Namentlich die deutsche Arbeiterklasse wird Moses Hess ein ehrendes Andenken bewahren. ${ }^{44}$

När det gäller frågan om vilket inflytande Hess haft på Marx, erkänner Mōnke nu-i motsats till vad han skrivit i den första upplagannästan inget sådant. ${ }^{45}$ Han står också fast vid sin negativa bedömning av Hess' sionistiska engagemang, trots att han i viss grad mildrat sina formuleringar. Nu heter det:

Diese Schrift [scil. Rom und Jerusalem], die die zionistische Bewegung einleitete, steht tief unter dem, was Hess vor der Revolution geschrieben. Hess konstruiert eine ausserhalb der ökonomischen und klassenmässigen Determiniertheit der bürgerlichen Gesellschaft stehende selbständige Kraft: die Nationalität. ${ }^{46}$

\section{Konklusioner}

Undersökningen har klart visat att Hess' sionistiska engagemang har lagts honom till last $i$ den marxistiska bedōmningen av honom. Detta är alldeles tydligt hos Julius Motteler, György Lukács, Irma Goitein och Wolfgang Mönke. Det är i alla fall inte sionismen som hos någon enda av dessa är det avgörande för att man har bedömt Hess negativt. Man kritiserar Hess i första hand för att han inte omfattade Marx' syn på socialismen, utan höll fast vid idealistiska tankar. Hess' sionism fungerar bara som ett tilläggsbevis på att han missat det väsentliga i socialismen.

Eduard Bernsteins och Ernst Blochs inställning till Hess ār intressant. Båda såg oerhört positivt på Hess, trots att de var motståndare till sionismen (Bernstein blev senare prosionist, men vid den tid han befattade sig med Hess var han antisionist). Bernstein bedömde Hess' socialistiska idéer positivt, vilken inte grumlades av att Hess senare blev sionist. Bloch igen lovordar Hess som en motpol till Herzl, som stod för en borgerlig sionism.

Vi sammanfattar: För ortodoxa marxister är Hess' kardinalsynd att hans uppfattning om socialismen avvek från Marx'. Hess' sionism är av sekundär betydelse. De som bedömer Hess' socialistiska tankar positivt ser inte hans sionism som ett hinder för att hylla honom. Summa summarum: Det är värre att avvika från den rātta läran i en central fråga än i en perifer. 


\section{NOTER}

* Artikeln baserar sig på ett föredrag hållet i den Fjärde nordiska kongressen i judaistik i Trondheim, 7-9 maj 1990.

1. Om detta inflytande, se Zwi Rosen 1983.

2. En kortfattad biografi över Hess är Svante Lundgren 1989. Av mer omfattande biografier är Edmund Silberners biografin par excellence (1966), baserad på mångårig forskning och materialsökning. En god analys av Hess' ideologiska utveckling är Shlomo Avineri 1985.

3. Geschichte der deutschen Arbeiterbewegung 1, 14. Andra exempel på nedvärdering av Hess ger Bruno Frei 1977, 119-127.

4. David McLellan 1973, 479.

5. Franz Mehring 1918, 120. Mehring berömmer Hess också i sitt verk om den tyska socialdemokratins historia, och påpekar att fördömandet av Hess i Kommunistiska manifestet var orättvist $(1960,245,247,311$, 343). Mehrings försvar av Hess har kritiserats av György Lukács (1926, 105f).

6. Att flera av den unga socialismens ledare âtminstone i viss utsträckning var antisemiter visar Edmund Silberner (1962) och Robert S. Wistrich (1976).

7. I Documente des Socialismus. 1. 1902, 533-552.

8. A.a., 536.

9. A.a., $535 f$.

10. Otryckta, Kautsky-Nachlass D XVII, 709a, 709b, $709 \mathrm{c}, 710$ och 711, IISG, Amsterdam.

11. Otryckta, Motteler-Nachlass Nr. 2244, IISG, Amsterdam.

12. Motteler till Kautsky 2.1. 1903, Kautsky-Nachlass

D XVII 709a.

13. Motteler till Kautsky 9.1. 1903, Kautsky-Nachlass D XVII 709c.

14. Ibid.

15. Пbid. Om Motteler här återger fru Hess' åsikt rätt är omöjligt att avgöra. Otänkbart är det inte eftersom Sibylle Hess var hängiven socialist men inte judinna.

16. Motteler till Kautsky, 7.1. 1903, Kautsky-Nachlass D XVII, 709b.

17. Motteler till Kautsky, 10.1. 1903, Kautsky-Nachlass D XVII 710 .

18. Citerat i Mottelers brev till Kautsky 2.1. 1903, Kautsky-Nachlass D XVII 709a.

19. Motteler till Kautsky, 10.1. 1903, Kautsky-Nachlass D XVII 710.

20. Se Edmund Silberner 1962, 213-220 (Bernstein), och 220-226 (Kautsky).
21. Motteler till Kautsky 20.1. 1903, Kautsky-Nachlass D XVII 711.

22. "Hier geschah nun das Unglaubliche: Menschen, die sich ihrer Achtung gegenüber Forschung und Wissenschaftlichkeit rühmten, widersetzten sich dem mit aller Kraft ... Wer sich den Zionisten nicht widersetzte, wie Eduard Bernstein, wurde verketzert.", Shlomo Na'aman 1982, 443.

23. Georg Lukács 1926.

24. A.a., 154.

25. Ibid. Vid ordet "Zionismus" har Lukács en not, i vilken han hänvisar till Zlocistis Hess-biografi, som han kallar flitig men principlös och förvirrande. Eftersom Zlocistis bok är mycket kritisk mot Marx kan man förstå Lukács' sura omdöme.

26. Irma Goitein 1931.

27. A.a., 2.

28. A.a., 105.

29. A.a., 4.

30. Ernst Bloch 1977.

31. A.a., 708.

32. A.a., 700 .

33. A.a., 711.

34. A.a., 713.

35. Angående detta, se Arno Münster 1989.

36. Moses Hess 1961.

37. Wolfgang Mönke 1964.

38. Wolfgang Mönke 1971. Sidorna 1-180 har varit tillgängliga. Enligt innehållsförteckningen omfattar dissertationen drygt 400 sidor.

39. Auguste Cornu \& Wolfgang Mönke: Einleitung, XXVI, XXXVIII och XLVI i Moses Hess 1961.

40. Wolfgang Mönke 1964.

41. Auguste Cornu \& Wolfgang Mönke: Einleitung, XXII, i Moses Hess 1961.

42. A.a., LXVII.

43. Auguste Cornu \& Wolfgang Mönke: Einleitung, LXVIII i Moses Hess 1961.

44. Wolfgang Mönke: Einleitung, CII i Moses Hess 1980.

45. A.a., XLVIII, LXIV, LXIXf.

46. A.a., CI. 


\section{LITTERATUR}

Otryckt

Kautsky-Nachlass, Internationaal Instituut voor Sociale Geschiedenis, Amsterdam

Brev:

Julius Motteler till Karl Kautsky 2.1. 1903 D XVII 709a

Julius Motteler till Karl Kautsky 7.1. 1903 D XVII 709b

Julius Motteler till Karl Kautsky 9.1. 1903 D XVII 709c

Julius Motteler till Karl Kautsky 10.1. 1903 D XVII 710

Julius Motteler till Karl Kautsky 20.1. 1903 D XVII 711

Motteler-Nachlass, Internationaal Instituut voor Sociale Geschiedenis, Amsterdam Brev:

Paul Trapp till Julius Motteler 5.12. 1902 och 8.1. 1903 Nr. 2244

Tryckt

\section{Avineri, Shlomo}

1985 Moses Hess : Prophet of Communism and Zionism. Modern Jewish Masters Series 1. New York and London

Bloch, Ernst

1977 Das Prinzip Hoffnung. Gesamtausgabe 5. Frankfurt am Main

\section{Documente}

1902 Documente des Socialismus : Hefte für Geschichte, Urkunde, und Bibliographie des Socialismus. Hrsg. von Eduard Bernstein. 1. Berlin

\section{Frei, Bruno}

1977 Im Schatten von Karl Marx : Moses Hess-hundert Jahre nach seinem Tod. Wien

Geschichte

1966 Geschichte der deutschen Arbeiterbewegung. 1. Von der Anfängen der deutschen Arbeiterbewegung bis zum Ausgang des 19. Jahrhunderts. Berlin

\section{Goitein, Irma}

1931 Probleme der Gesellschaft und des Staates bei Moses Hess Beiheft zum Ar- chiv für die Geschichte des Sozialismus und der Arbeiterbewegung. 5. Leipzig

\section{Hess, Moses}

1961 Philosophische und sozialistische Schriften 1837-1850 : eine Auswahl. Hrsg. und eingel. von Auguste Cornu/ Wolfgang Mönke. Berlin

1980 Philosophische und sozialistische Schriften 1837-1850: eine Auswahl. Hrsg. und eingel. von Wolfgang Mönke. Zweite, bearbeitete Aufl. Vaduz

\section{Lukács, Georg}

1926 Moses Hess und die Probleme der idealistischen Dialektik. Archiv für die $\mathrm{Ge}$ schichte des Sozialismus und der Arbeiterbewegung. 12, 105-155. [Ingår också i Georg Lukács, Geschichte und Klassenbewusstsein. Georg Lukács Werke, 2. Neuwied und Berlin 1968]

Lundgren, Svante

1989 Moses Hess-jude och socialist. Nordisk Judaistik 10, 75-93

\section{McLellan, David}

1973 Karl Marx : his life and thought. London and Basingstoke

\section{Mehring, Franz}

1918 Karl Marx : Geschichte seines Lebens. Leipzig

1960 Geschichte der deutschen Sozialdemokratie. 1. Von der Julirevolution bis zum preussischen Verfassungsstreite 1830 bis 1863 . Gesammelte Schriften 1. Berlin

\section{Münster, Arno}

1989 Ernst Bloch—oder: Das philosophischpolitische Erbe von Moses Hess als Korrektiv zum politischen Programm des Zionismus. Judaica 45, 221-241

Mönke, Wolfgang

1964 Neue Quellen zur Hess-Forschung. Mit Auszügen aus einem Tagebuch, aus Manuskripten und Briefen aus der Korrespondenz mit Marx, Engels, Weitling, Ewerbeck u.a. Abhandlungen der Deutsche Akademie der Wissenschaften zu Berlin. Klasse für Philosophie, Geschichte, Staats-, Rechts- und Wirtschaftswissenschaften. 1964:1. Berlin

1971 Der "wahre" Sozialismus. Teil 1. Moses Hess 1812-1844. maskinskriven 


\author{
dissertation. Berlin \\ Na'aman, Shlomo \\ 1982 Emanzipation und Messianismus. Le- \\ ben und Werk des Moses Hess. Quel- \\ len und Studien zur Sozialgeschichte. \\ 3. Frankfurt a.M. \& New York
}

Rosen, Zwi

1983 Moses Hess und Karl Marx : ein Beitrag zur Entstehung der Marxschen Theorie. Hamburg

Silberner, Edmund

1962 Sozialisten zur Judenfrage : ein Beitrag zur Geschichte des Sozialismus vom Anfang des 19. Jahrhunderts bis 1914. Aus dem Englischen übers. von Arthur Mandel. Berlin

1966 Moses Hess : Geschichte seines Lebens. Leiden

Wistrich, Robert S.

1976 Revolutionary Jews from Marx to Trotsky. London

\section{Zusammenfassung}

Gibt es Antizionismus in der marxistischen Kritik des Moses Hess?

Einer von der bedeutendsten Protozionisten, der Verfasser des zionistischen Klassikers Rom und Jerusalem, Moses Hess (1812-75), war zugleich ein leitender Sozialist seiner Zeit. Dieser "Vater der deutschen Sozialdemokratie" wurde von seinen ehemaligen Freunde Marx und Engels im Kommunistischen Manifest sehr heftig angegriffen.

Wegen dieses Angriffs ist Hess in der offizi- ellen sozialistischen Geschichts-schreibung und von marxistischen Forschern sehr negativ behandelt geworden. Ein Beispiel ist dass Hess im grossen Werk über der Geschichte der deutschen Arbeiterbewegung, herausgegeben von der Institut für Marxismus-Leninismus beim Zentralkomitee der SED, nur einmal erwähnt wird. Es gibt natürlich auch einige Ausnahmen von dieser Regel, z.B. der bekannte Historiker Franz Mehring.

In diesem Artikel ist die Frage, ob es antizionistische Merkmale in der marxistischen Kritik des Moses Hess gibt, untersucht. Ist die Tatsache, dass Hess später engagierter Zionist war, bei Marxisten als ein Beleg für die Auffassung, dass Hess niemals den "wissenschaftlichen Sozialismus" verstand, benutzt geworden?

Die Untersuchung zeigt dass Hess' Zionismus bei marxistischen Forschern sehr negativ beurteilt worden ist. Das ist ganz deutlich bei Julius Motteler, György Lukács, Irma Goitein und Wolfgang Mönke. Die Ausnahmen sind Eduard Bernstein und Ernst Bloch.

Bernstein unterstützte die Planen von einigen Zionisten, um Artikels von und eine Biographie über Hess herauszugeben. Bernstein hochachtete die sozialistische Ideen von Hess, trotz seinen antizionistischen Meinungen. (Die Erwähnungen über Hess sind aus dem Beginn dieses Jahrhunderts, als Bernstein Antizionist war. Später wurde er prozionistisch.)

Bloch war-wie die meisten MarxistenAntizionist, aber er war offenbar von Hess' Synthese von jüdischen Prophetismus und revolutionäre Sozialismus sehr imponiert.

Die Ursache warum die meisten Marxisten Hess sehr kritisch beurteilen ist nicht sein Zionismus, sondern sein von Marx abweichende Auffassung des Sozialismus. Sein zionistisches Engagement aber ist ein Zusatzbeweis gegen ihn. 